\title{
Research Paper On generalized logarithmic series distribution and its application to leaf spot grades in mulberry
}

See end of the paper for authors' affiliations

Correspondence to : FEHIM JEELANI WANI

Division of Agricultural Statistics, Faculty of Horticulture, Shalimar, Sher-e-Kashmir University of Agricultural Sciences and Technology (K), SRINAGAR (J\&K) INDIA

Email : faheemwani149@ gmail.com

\section{Paper History :}

Received : 06.01.2017;

Revised : 17.01.2017;

Accepted : 27.01 .2017
Abstract : The generalized logarithmic series distribution (GLSD) adds an extra parameter to the usual logarithmic series distribution and was introduced by Jain and Gupta (1973). This distribution has found applications in various fields. The estimation of parameters of generalized logarithmic series distribution was studied by the methods of maximum likelihood, moments, minimum chi-square and weighted discrepancies. The GLSD was fitted to different leaf spot grades in four varieties of mulberry namely Ichinose, Gosherami, Rokokuvoso and Kokuso-20 and it was observed that all the estimation techniques perform well in estimating the parameters of generalized logarithmic series distribution but with varying degree of non-significance.

KEY Words : Generalized logarithmic series distribution, Leaf spot grades, Mulberry

How To Cite This Paper : Wani, Fehim Jeelani, Raja, T.A., Maqbool, Showket, Khan, Imran and Bhat, M. Iqbal Jeelani (2017). On generalized logarithmic series distribution and its application to leaf spot grades in mulberry. Internat. Res. J. Agric. Eco. \& Stat., 8 (1) : 60-64, DOI : 10.15740/HAS/IRJAES/8.1/60-64. 